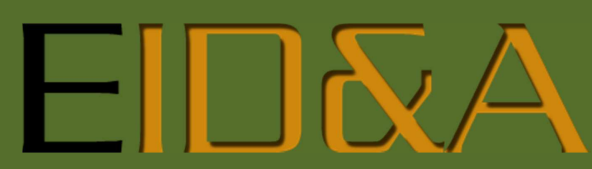

Revista Eletrônica de Estudos Integrados em Discurso e Argumentação

dx.doi.org/10.17648/eidea-16-2225

\title{
A IMPOSIÇÃO DE REFORMAS E A MIDIATIZAÇÃO: O ENSINO MÉDIO NO BRASIL ENTRE CONSENSOS E RESISTÊNCIAS
}

\author{
Vanice Sargentini ${ }^{\mathrm{i}}$
}

\begin{abstract}
Resumo: Problematizando as formas como são produzidas e circulam as notícias sobre Reformas Políticas, analisaremos a Campanha da Reforma do ensino médio, feita pelo Governo Michel Temer no Brasil. A Medida Provisória (MPV) $n^{\circ} 746$, de 2016, ao ser apresentada de forma midiática à população brasileira, desencadeou discursos que expuseram o confronto das relações de poder inscritas no corpo docente e discente, nas expectativas políticas e empresariais, nos imaginários sobre o que se deve saber. Na mídia tradicional essas relações de poder tendem à defesa de um sistema de controle disciplinar (do corpo, do tempo e da vida) regido pelo pensamento capitalista liberal, obliterando o pensamento científico, pedagógico e acadêmico. Nossa hipótese é a de que o mesmo discurso que na mídia tradicional promove o discurso eufórico de valorização do tempo na escola, sustenta negativamente o discurso dos alunos que resistem, impondo a esses o discurso de que ao ocuparem as escolas estariam defendendo a dissipação do tempo por meio da intemperança, imprevidência e desordem e com isso a mídia tradicional obscurece a possibilidade de se reconhecer nesse ato a defesa de uma outra posição.
\end{abstract}

Palavras-chave: Discurso político. Reforma do Ensino Médio. Resistência.

\begin{abstract}
By problematizing the ways of production and circulation of the news about Political Reforms, we will analyze the Michel Temer Government High School Reform Campaign in Brazil. The Provisional Measure (MPV) n. 746 of 2016, when presented in a media way to the Brazilian population, instigated discourses that exposed the confrontation of the power relations registered in the teaching staff and students corporation, in the political and business expectations, in the imaginary about what should be known. In traditional media these power relations tend to defend a system of disciplinary control (of the body, the time and the life) governed by liberal capitalist thinking and obliterating a scientific, pedagogical and academic thinking. Our hypothesis is that the same discourse that in the traditional media promotes the euphoric discourse of valuing time in school negatively supports the discourse of students who resist, imposing on these students the discourse that when they occupy the schools they would be defending the dissipation of time through intemperance, negligence and disorder. Moreover, with this operation the traditional media obscure the possibility of recognizing in this act the defense of another position.
\end{abstract}

Keywords: Political discourse. High School Reform. Resistance.

'Docente da Universidade Federal de São Carlos (UFSCar), Brasil. Email: sargentini@uol.com.br. 
EID\&A - Revista Eletrônica de Estudos Integrados em Discurso e Argumentação, Ilhéus, n. 16 esp. "Discurso e argumentação na política latino-americana, set.2018.

\section{Introdução}

O giro à esquerda iniciado no Brasil em 2002, com a eleição do então candidato Luiz Inácio Lula da Silva à presidência, passou ao longo dos anos seguintes por seu apogeu seguido de abalos que vieram a tirar de assalto a prevalência de um pensamento progressista de esquerda e instalar um ideário de direita que recupera a voz do conservadorismo brasileiro (AB'SABER, 2015) ancorado em uma política de ódio. A assunção de Michel Temer ao cargo de presidente, após o impeachment de Dilma Rousseff, desencadeou uma política gerida por Reformas: do Ensino Médio, da Previdência, Trabalhista. Em todas essas propostas de reformas estão envolvidas as formas de controle e vigilância e a questão do tempo que será sequestrado do cidadão (FOUCAULT, 2015).

A Medida Provisória (MPV) $n^{0}$ 746, de 22 de setembro de 2016, que "promove alterações na estrutura do ensino médio, última etapa da educação básica, por meio da criação da Política de Fomento à Implementação de Escolas de Ensino Médio em Tempo Integral" (Senado, 2016), ao ser apresentada de forma midiática à população brasileira, desencadeou discursos que expuseram o confronto das relações de poder inscritas no corpo docente e discente, nas expectativas políticas e empresariais, nos imaginários sobre o que se deve saber. Na mídia tradicional essas relações de poder tendem à defesa de um sistema de controle disciplinar (do corpo, do tempo e da vida) regido pelo pensamento capitalista liberal, obliterando o pensamento científico, pedagógico e acadêmico. Ademais, a justificativa para a reforma pauta-se em um suposto desejo discente de revisão de controle do seu tempo; justamente o tempo que possibilita o sequestro da vida a ser transformada em força de trabalho (FOUCAULT, 2015).

O dissenso sobre a Medida Provisória é nosso objeto de análise, que será apresentado com base na coleta de material extraído de Audiências Públicas sobre o tema e material publicado na mídia em campanha publicitária do Governo. Nossa hipótese é a de que o mesmo discurso que na mídia tradicional promove um dizer eufórico de valorização do tempo na escola, sustenta negativamente o discurso dos alunos que resistem, impondo a esses o discurso de que ao ocuparem as escolas (ação recorrente no ano de 2016 em escolas de Ensino Médio brasileiras) estariam defendendo a dissipação do

\footnotetext{
${ }^{1}$ https://www25.senado.leg.br/web/atividade/materias/-/materia/126992
} 
EID\&A - Revista Eletrônica de Estudos Integrados em Discurso e Argumentação, Ilhéus, n. 16 esp. "Discurso e argumentação na política latino-americana, set.2018.

tempo por meio da intemperança, imprevidência e desordem (FOUCAULT, 2015), e com isso a mídia tradicional obscurece a possibilidade de se reconhecer nesse ato a defesa de uma outra posição.

A reflexão de M. Foucault (2015) sobre a sequestração do tempo contribuirá teoricamente para a análise do funcionamento das práticas discursivas que circulam na sociedade contemporânea por meio dos diversos processos de midiatização do discurso político. As tensões sobre o discurso midiático e a política, conforme Courtine (2006), Piovezani (2009) e Sargentini (2017) serão consideradas como presenças constitutivas nos meios de comunicação que atuam reafirmando, por diferentes práticas discursivas, as lutas pelo poder.

\section{Discurso e Poder: a sequestração do tempo segundo Foucault}

Pautados em reflexões sobre a Sociedade Punitiva (FOUCAULT, 2015) e a Sociedade Disciplinar (FOUCAULT, 2008), propomos problematizar como, na sociedade contemporânea, defendem-se diferentes posicionamentos sobre as razões e formas de 'sequestração' do tempo (para empregar uma expressão presente em suas aulas). Focalizando como tema o encaminhamento de Reformas, trataremos de modo específico da Reforma do Ensino Médio, analisando-a seja em sua formulação, em discussões em audiência pública no Senado, seja em sua circulação em textos de campanhas midiáticas governamentais.

Algumas inquietações orientaram a proposição deste artigo: $\mathrm{o}$ que a sequestração do tempo tem a ver com a Reforma do Ensino Médio? A Reforma do Ensino Médio regula o tempo e o conteúdo? Parece-nos que não só! Regula também a moral, o corpo e a vida. As Instituições Estatais regulam a sociedade ou são reguladas por interesses empresariais? Quais são as práticas discursivas envolvidas no confronto sobre a Reforma do Ensino Médio?

Em A Sociedade Punitiva, Foucault (2015) expõe que a noção de direito ao tempo emerge juntamente com a proposição de reclusão que se estabelece na instalação do encarceramento como uma forma consensual de punição. Trata-se de excluir o infrator da sociedade e dele extrair o seu tempo. Mede-se o tempo: durante quanto tempo alguém deve ficar recluso como consequência de uma infração? Qual será sua pena? 
EID\&A - Revista Eletrônica de Estudos Integrados em Discurso e Argumentação, Ilhéus, n. 16 esp. "Discurso e argumentação na política latino-americana, set.2018.

[...] assim como se dá um salário pelo tempo de trabalho, toma-se, inversamente, certo tempo de liberdade como preço de uma infração. [...] Sendo o único bem possuído, o tempo é comprado em razão do trabalho ou tomado em razão de uma infração.

$[\ldots]$

Quero simplesmente dizer que a forma-prisão e a forma-salário são formas historicamente gêmeas, sem que se possa dizer ainda quais são suas relações. (FOUCAULT, 2015, p.65)

O que se observa pela leitura dessas aulas de Foucault, ministradas no Collège de France, no ano de 1973, é que sendo o encarceramento uma pena a ser aplicada por um determinado período, passa-se a introduzir a necessidade do controle do tempo, e também da vida e do corpo do indivíduo no exercício do poder disciplinar.

O tempo é permutado com o poder. [E,] por trás da forma-salário, a forma de poder posta em prática pela sociedade capitalista tem essencialmente por objeto exercer-se sobre o tempo dos homens: a organização do tempo operário na fábrica, a distribuição e o cálculo desse tempo no salário, o controle do lazer da vida operária, a poupança, as aposentadorias, etc. Essa maneira como o poder enquadrou o tempo para poder controlá-lo por inteiro possibilitou historicamente e [em termos de] relações de poder, a existência da formasalário. Foi preciso essa tomada de poder global sobre o tempo. Assim, o que nos permite analisar de forma integrada o regime punitivo dos delitos e o regime disciplinar do trabalho é a relação do tempo de vida com o poder político: essa repressão do tempo e pelo tempo é a espécie de continuidade entre o relógio de ponto, o cronômetro da linha de montagem e o calendário da prisão. (FOUCAULT, 2015, p.66-67)

E acrescentaríamos no interior dessa 'fina vigilância'- o tempo estabelecido para a formação escolar! E, vejamos, talvez não seja por simples coincidência que as medidas iniciais do governo Michel Temer, a partir do segundo semestre de 2016, tenham recaído exatamente sobre o tempo - o tempo das horas de trabalho na proposta de Reforma Trabalhista, o tempo para atingir a aposentadoria, na Reforma Previdenciária, o tempo dos alunos nas escolas, na Reforma do Ensino.

Na aula de 21 de março de 1973, Foucault, ao falar das Instituições de reclusão (pedagógicas, corretivas, terapêuticas) faz referência à semelhança existente entre os regulamentos dessas instituições. Em uma primeira nota de rodapé, há a retomada da fala de Foucault em sua conferência no Rio de Janeiro, em que diz: "Vou propor uma adivinhação. Apresentarei o regulamento de uma instituição que de fato existiu nos anos 1840-1845 na França, [...] sem dizer se se trata de fábrica, prisão, hospital psiquiátrico, convento, escola, 
EID\&A - Revista Eletrônica de Estudos Integrados em Discurso e Argumentação, Ilhéus, n. 16 esp. "Discurso e argumentação na política latino-americana, set.2018.

caserna; é preciso adivinhar de que instituição se trata" (FOUCAULT, 2015, p. 201).

Essa semelhança entre as instituições dá-se pelos regulamentos, mas também pela arquitetura, pela vigilância contínua, pelos exames, pelo controle da organização do tempo e pelo atravessamento das relações de poder a que essas instituições estão suscetíveis em um sistema capitalista.

Nessa grande empreitada de reclusão, na primeira metade do século XIX, estavam também incluídas as instituições pedagógicas (creches, colégios, orfanatos) que em conjunto com as instituições corretivas e terapêuticas garantiam o "enquadramento constante do indivíduo desde o nascimento até a morte" (FOUCAULT, 2015, p.188).

A reclusão do século XIX tem formas distintas daquelas do período clássico, quando havia um sentimento de pertencimento a um grupo, a castas, a comunidades e eram esses que regiam a vigilância, estabelecendo regras, comportamentos e punições. No século XIX, "logo que [os cidadãos] nasciam eram colocados numa creche; na infância, enviados à escola; iam para a fábrica; durante a vida toda, pertenciam a uma agência de beneficência; podiam fazer depósitos numa caixa econômica, acabavam no asilo." (FOUCAULT, 2015, p. 188).

As referências da vida passam a ser relacionadas às instituições, não são mais corpos sociais com o sentimento de pertencimento a um grupo, tampouco corpos produtores, mas passam a ser corpos que atuam como multiplicadores de poder. Assim, as instituições funcionam como aquelas que propiciam estágios de poder de uma classe sobre a outra, de um grupo sobre outro. Algumas instituições parecem ganhar superpoderes para além do aparato do Estado: um excedente de poder.

Além dessa mudança, no século XIX, outra mudança se dá: os indivíduos são distribuídos e fixados em aparatos sociais.

A criança que fosse colocada numa colônia agrícola, o jovem operário que fosse posto numa fábrica-convento, o individuo que fosse enviado para uma penitenciária onde houvesse oficinas na realidade estavam sendo fixados num aparato produtivo. A criança mandada para a escola era fixada num aparato que transmitia saber, que normatizava. [...]Supunha-se que a maioria dos colégios onde as crianças eram internadas estava conectada a certo aparato de transmissão do saber e que só eram marginalizados aqueles que resistiam a essa transmissão. A máquina trabalhava para desmarginalizar, e a marginalização era apenas um efeito colateral. (FOUCAULT, 2015, p.191). 
EID\&A - Revista Eletrônica de Estudos Integrados em Discurso e Argumentação, Ilhéus, n. 16 esp. "Discurso e argumentação na política latino-americana, set.2018.

E com isso as instituições ultrapassavam os seus poderes: vigiavam e julgavam moralmente aqueles que resistissem à normatização.

$O$ aluno que é mandado para a escola deve submeter-se a esse aparato pedagógico, no qual ele receberá o saber escolar, que pretende a normatização. Entretanto para tal é preciso que o tempo da vida seja regulado para atender ao tempo da produção. É isso que Foucault tratará por instituições que atuam na 'sequestração do tempo'. Já não se trata da reclusão do aluno na escola, mas da fixação desse aluno por certo tempo. Para isso são vários e dispersos os instrumentos de sequestração.

- Duração do tempo de formação;

- Frequência exigida;

- Disciplinas a serem aprendidas;

- Exames regulares e habilitadores;

- Premiações, competições;

- Reconhecimento Social e Institucional.

Além disso, esses instrumentos expandem-se e parecem escapar ao Estado, sendo tomados pela iniciativa privada, que continua ao mesmo tempo contando com o modelo escolar e o amparo estatal.

Em relação à fixação do trabalhador na fábrica, criam-se as "caixas econômicas (para as poupanças) e as caixas de previdência. O esforço para economizar afasta o trabalhador dos excessos (festas, farras, concubinatos) e, portanto garante uma produção contínua e que o mantem ligado ao trabalho ao longo do tempo estabelecido para ele retirar seus valores da caixa de previdência.

A sequestração do tempo na sociedade capitalista teve, segundo Foucault (2015), três funções principais:

- Organizar e sujeitar o tempo da existência dos homens a esse sistema temporal do ciclo de produção. Não se trata mais somente de fixar os indivíduos ao local, mas ao tempo de interesse da produção (sequestração temporal);

- Manter o controle direto ou indireto da existência. As instituições ultrapassam suas atribuições e vigiam aquilo que não lhes diz respeito, em especial o corpo, a sexualidade e as relações interindividuais. E assim produzia-se uma discursividade sobre o 
EID\&A - Revista Eletrônica de Estudos Integrados em Discurso e Argumentação, Ilhéus, n. 16 esp. "Discurso e argumentação na política latino-americana, set.2018.

comportamento dos indivíduos, relacionado à moral, como uma forma complementar de julgamento;

- Produzir um discurso da normatividade, que toma o indivíduo do começo ao fim da existência, sendo que esse discurso não é produzido por ele mesmo, mas por autoridades hierárquicas inscritas no próprio sistema de sequestração.

Esse funcionamento iniciado no século XIX segue aprimorando-se nos séculos seguintes. Aos poderes inscritos no seio do Estado - Legislativo, Executivo e Judiciário - observamos que "nas sociedades democráticas modernas, criamos o habito de acrescentar-lhes outras duas formas de poder: o econômico e o midiático" (TODOROV, 2012, p.138). Se há enfrentamentos entre os poderes de Estado, entre esses e os poderes midiático e econômico é mais provável uma aliança e isso pode reduzir discursos de confronto, em "palavras lisas como a pedra", para empregar uma metáfora de Foucault (2003), palavras pelas quais se expressam um dominante consenso.

2. O que não circula na mídia: as audiências públicas sobre a Reforma do Ensino Médio

A escola não escapa, então, a esse sistema de sequestração do tempo e de vigilância. Assim, a sociedade disciplinar vai respondendo aos interesses do capitalismo, que por sua vez tem suas necessidades. Considerando as ponderações de Foucault (2015), observamos, por exemplo, que não se encontra a força de trabalho pronta na sociedade; é preciso formar e fixar geograficamente essa força de trabalho.

Nossa suposição é a de que, na essência, essas características das instituições, os anseios capitalistas e os interesses de sequestração do tempo se mantêm na atualidade. E para compreendermos o funcionamento dos instrumentos de sequestração do tempo, passaremos a fazer um cotejamento com o que se passa na educação brasileira a respeito da MP 746/2016, que se refere à reforma do ensino médio.

A Ementa que tramitou no Congresso foi a seguinte:

EMENTA: Institui a Política de Fomento à Implementação de Escolas de Ensino Médio em Tempo Integral, altera a Lei $n^{\circ}$ 9.394, de 20 de dezembro de 1996, que estabelece as diretrizes e bases da educação nacional, e a Lei $n^{\circ} 11.494$ de 20 de junho 2007, que regulamenta o Fundo de Manutenção e Desenvolvimento da 
EID\&A - Revista Eletrônica de Estudos Integrados em Discurso e Argumentação, Ilhéus, n. 16 esp. "Discurso e argumentação na política latino-americana, set.2018.

Educação Básica e de Valorização dos Profissionais da Educação, e dá outras providências.

EXPLICAÇÃO DA EMENTA: Promove alterações na estrutura do ensino médio, última etapa da educação básica, por meio da criação da Política de Fomento à Implementação de Escolas de Ensino Médio em Tempo Integral. Amplia a carga horária mínima anual do ensino médio, progressivamente, para 1.400 horas. Determina que o ensino de língua portuguesa e matemática será obrigatório nos três anos do ensino médio. Restringe a obrigatoriedade do ensino da arte e da educação física à educação infantil e ao ensino fundamental, tornando as facultativas no ensino médio. Torna obrigatório o ensino da língua inglesa a partir do sexto ano do ensino fundamental e nos currículos do ensino médio, facultando neste, o oferecimento de outros idiomas, preferencialmente o espanhol. Permite que conteúdos cursados no ensino médio sejam aproveitados no ensino superior. O currículo do ensino médio será composto pela Base Nacional Comum Curricular - BNCC e por itinerários formativos específicos definidos em cada sistema de ensino e com ênfase nas áreas de linguagens, matemática, ciências da natureza, ciências humanas e formação técnica e profissional. Dá autonomia aos sistemas de ensino para definir a organização das áreas de conhecimento, as competências, habilidades e expectativas de aprendizagem definidas na BNCC.

Assim que divulgada, a proposta de Medida Provisória (MP) causou grande alarde na sociedade que se perguntava: nós pedimos isso? Isso é relevante? Isso é realmente urgente? Questionou-se: Por que a implementação de tempo integral agora? Algo que não parecia imediatamente coerente, uma vez que simultaneamente estava em tramitação no Congresso a PEC 241/55, que aprovou da manutenção do teto dos gastos por 20 anos.

$\mathrm{Na}$ seleção dos enunciados que vieram a compor nosso corpus de análise, recorremos inicialmente ao próprio documento da MP e ao vídeo (disponível na rede) da $2^{\mathrm{a}}$ Audiência Pública da Comissão Mista para examinar a MP 746, cujo relator é Pedro Chaves. Na $1^{\text {a }}$ audiência foram convidados 3 representantes do governo federal, alguns profissionais da área da educação, dirigentes, presidentes (CNE) e um consultor legislativo. Para a segunda Audiência foram convidados:

- Ronaldo Motta - Reitor da Universidade Estácio de Sá

- Wilson de Matos Silva (ex-senador) - Reitor da UNICESUMAR

- Maria Alice Setubal - Presidente do CENPEC -Centro de estudos e Pesquisas em Educação

- Ricardo Henriques - Superintendente executivo do Instituto UNIBANCO 
EID\&A - Revista Eletrônica de Estudos Integrados em Discurso e Argumentação, Ilhéus, n. 16 esp. "Discurso e argumentação na política latino-americana, set.2018.

- Danival Roberto Alves - Diretor do Colégio CENESISTA - Dr. José Ferreira - MG

- Mariza Abreu - Consultora Legislativa

Iremos nos ater à análise da $2^{\mathrm{a}}$ Audiência, presidida pelo Deputado Izalci, no dia 08/11/2016 ${ }^{2}$. Como dissemos anteriormente, contamos com a atualidade do pensamento de Foucault sobre a sequestração do tempo para a premissa de nossa análise. A emenda começa por: Amplia a carga horária mínima anual do ensino médio, progressivamente, para 1.400 horas. Controla o tempo do aluno na instituição pedagógica que deve garantir a produtividade. A segunda parte da MP, trata da flexibilização, tendo sido um ponto alto da polêmica, pois entrará em vigência somente após a aprovação da Base Nacional Comum Curricular (BNCC) - que está ao longo do ano de 2017 em discussão e não tem prazo para conclusão.

A ampliação da carga horária, segundo a Consultora Legislativa Mariza Abreu, atingirá um número máximo de 572 escolas (dentre as 19.513) e 257 mil alunos, o que significa $3 \%$ dos alunos atendidos. Os repasses financeiros serão feitos em duas parcelas e depois caberá aos municípios a continuidade das ações. Como essa reforma não atingirá todas as escolas e alunos, estabelecese e fortalece-se a desigual relação de poder entre escolas, professores e alunos. A proposta é feita pelo Estado, mas não se dá sem a central participação de instituições de iniciativa privada, que se apoiam nos aparatos estatais, que é uma condição de funcionamento das próprias instituições.

A forma-salário retorna à discussão. A sequestração do tempo escolar é regida por diferentes discursos.

- Dar o seu tempo à escolarização: o que significa ampliar o tempo de estudo, que como sabemos é forte fonte de qualificação nas relações de poder;

- Dar o seu tempo para estudar um determinado conteúdo: o que significa não focalizar a ampliação do conhecimento geral, mas investir em uma parte do conhecimento.

São esses dois discursos que são mantidos na MP: a proposta de estudar por mais tempo (e isso atingiria 3\% dos alunos atendidos); e a proposta de

\footnotetext{
${ }^{2}$ O vídeo completo da Audiência Pública pode ser assistido em https://www.youtube.com/watch?v=L3laLYSFSol\&t=5439s. Em 31/07/2017, o vídeo possuía 2381 visualizações.
} 
EID\&A - Revista Eletrônica de Estudos Integrados em Discurso e Argumentação, Ilhéus, n. 16 esp. "Discurso e argumentação na política latino-americana, set.2018.

estudar por itinerários formativos, conforme oferta da escola, o que significa que nem todas as escolas terão plenas condições de ofertar a opção de escolha entre as quatro (4) áreas de conhecimento ${ }^{3}$. Nesse segundo caso, os alunos, que supostamente teriam a ilusão de escolher em que investir o seu tempo, terão, de forma incontornável, que seguir o itinerário formativo que Ihe for oferecido na escola próxima.

$\mathrm{Na}$ MP, o texto expõe essa impossibilidade de escolha, quando indica que cada sistema de ensino definirá os itinerários formativos e a organização das áreas:

O currículo do ensino médio será composto pela Base Nacional Comum Curricular - BNCC e por itinerários formativos específicos definidos em cada sistema de ensino e com ênfase nas áreas de linguagens, matemática, ciências da natureza, ciências humanas e formação técnica e profissional.Dá autonomia aos sistemas de ensino para definir a organização das áreas de conhecimento, as competências, habilidades e expectativas de aprendizagem definidas na BNCC.

Para discutir a pertinência da Reforma, na segunda audiência, estão presentes Reitores de Universidades particulares e representantes de Institutos formados com apoio empresarial. Algumas afirmações são ditas por esses convidados de modo consensual e sem amparo estatístico, como a de que "o Brasil tem o pior ensino do mundo". A justificativa de quanto tempo o aluno deverá ficar na escola e que conteúdos deverá aprender passa por um julgamento intelectual e social. A questão moral também justifica a sequestração do tempo. Segundo o reitor Wilson Matos Silva, da UNICESUMAR, em Audiência Pública

[...] o Brasil tem o pior ensino do mundo. A maior parte é aprovada pelo Conselho de Classe, os outros que passam só o conseguem porque colam (90\%). É preciso desmembrar por área de saberes, mesmo porque"nem todos têm vocação para o teórico - bacharel são os auxiliares do Rei".

A mudança justifica-se pelo rebaixamento moral dos estudantes. A emergência no enunciado do termo 'nem todos', faz pressupor quesó alguns têm vocação para o teórico. Discurso que se alinha às razões (e direitos) da

\footnotetext{
${ }^{3}$ As disciplinas obrigatórias nos 3 anos de ensino médio serão língua portuguesa e matemática. 0 restante do tempo será dedicado ao aprofundamento acadêmico nas áreas eletivas ou a cursos técnicos, a seguir: I - linguagens e suas tecnologias; II - matemática e suas tecnologias; III ciências da natureza e suas tecnologias; IV - ciências humanas e sociais aplicadas; V - formação técnica e profissional. Cada estado e o Distrito Federal organizarão os seus currículos considerando a BNCC e as demandas dos jovens, que terão maiores chances de fazer suas escolhas e construir seu projeto de vida. (http://portal.mec.gov.br/component/content/article?id=40361 Acesso em: 2 ago.2017).
} 
EID\&A - Revista Eletrônica de Estudos Integrados em Discurso e Argumentação, Ilhéus, n. 16 esp. "Discurso e argumentação na política latino-americana, set.2018.

manutenção da desigualdade (supõe-se que os alunos não são sérios - colam - e não têm vocação). A discussão toma o rumo da moral e da penalidade pela moral.

Ronaldo Mota, reitor da Universidade Estácio de Sá, diz quenosso ensino médio é provavelmente o pior do mundo. E traz um longo exemplo de como se dá o ensino na Inglaterra, onde se deixa que os alunos escolham se farão biologia, química ou física, mas que isso não teria problema, porque depois o professor ensina transversalmente a física e a química,"o objetivo é o aluno gostar, sentir que escolheu". Veja, a imagem que se tem desse aluno é de alguém a quem se basta fazer com que ele tenha 'sentido que escolheu'. Sugere que o que falta aos professores é empatia e que se deve discutir a analítica da aprendizagem. Em relação à oferta do ensino técnico, será a fixação do aluno em uma dada região que poderá render frutos à produção e, portanto, o tempo que lhe será sequestrado no percurso de ensino laprendizagem já estará incorporado ao tempo e investimento que a indústria/empresa teria que investir na sua formação. E atentemos, é possível compreender porque se inflamou um movimento estudantil de tamanha ordem nas escolas de Ensino Médio brasileiras. O aluno não é tratado com respeito, mas objetivado como alguém que deverá entrar na norma ou ficar na margem. Segundo Foucault (2015), essa é a forma pela qual se cria o aparato para desmarginalizar e a marginalização é seu efeito colateral.

É interessante também analisar como o representante de um Instituto pondera sobre a MP. Trata-se de Ricardo Henriques - Superintendente Executivo do Instituto Unibanco. Para ele,

[...] poucos fazem o ensino médio (63\%), muito não ficam e os que ficam pouco aprendem. É preciso dar conta do interesse do jovem. [Insiste repetidas vezes que] são as Práticas de Ensino e a Didática que devem ser reestruturadas e que os cursos de Pedagogia e Licenciatura resistem. [E que é preciso] rediscutir a formação dos professores. [...]

[É preciso] uma nova cultura da gestão pública que tire a autonomia da escola.

Consideramos que quem diz isso é a voz do poder empresarial, que atravessa o aparato estatal. As críticas feitas pelo superintendente do UNIBANCO são de caráter genérico e as falhas têm sujeitos responsabilizados - professores formadores e reflexão acadêmico-científica. Quem sabe sobre isso não é aquele que se dedicou ao conhecimento científico, mas a experiência da iniciativa privada. 
EID\&A - Revista Eletrônica de Estudos Integrados em Discurso e Argumentação, Ilhéus, n. 16 esp. "Discurso e argumentação na política latino-americana, set.2018.

Enfim, é a intervenção do discurso da iniciativa privada, valendo-se do modelo estatal. O chamamento para a audiência pública de grupos Institucionais que, supostamente por serem sem fins lucrativos seriam a imagem da benevolência voluntariosa, faz entrever o interesse que há em atender aos interesses empresariais.

Nesta segunda audiência pública, a explicitação dessa relação interesseira entre a form-ação e a forma-salário veio de forma exemplar da intervenção da Deputada Profa. Dorinha Seabra Rezende (DEM) de Tocantins:

É preciso reorganizar todo material didático e toda a formação de professores. [...] O desafio é a autonomia universitária. Fui secretária e quantas vezes tive que contratar universidade para formar os professores do jeito que a escola precisa.

Os professores e diretores de escolas não têm voz autorizada nesta hierarquia para falar. A pesquisa científica sobre os conteúdos e formas pedagógicas são sempre comentadas pelo outro - o superintendente do Instituto, o Reitor da Universidade -, enfim um indício da parceria público privado a conduzir o tempo, o método, a formação e em última instância o desejo, a cumplicidade do aluno, para garantir que "Tenha-se aí um meio de coerção ética e política necessária para que o corpo, o tempo, a vida e os homens sejam integrados no jogo de forças produtivas". (FOUCAULT, 2015, p. 180)

Em desacordo com os outros debatedores, a consultora legislativa Mariza Abreu assim se refere:

(No Brasil) Desvalorizamos o artesanato e supervalorizamos o nível superior. [...] Até que ponto é a LDB que impede a flexibilização? Ou é a cultura arraigada na sociedade brasileira e uma concepção de nobreza portuguesa que impera no Brasil?" [...] Como flexibilizar sem aumentar a desigualdade?

Assim, há uma questão histórica (sempre há) que inscreve o sujeito de forma desigual na sociedade. $O$ assunto deve ser debatido, não há dúvida. $A$ MP da reforma do Ensino Médio reafirma a desigualdade de oferta, uma vez que o Período Integral não é para todos e o Itinerário Formativo ficará a cargo dos interesses da iniciativa privada. Isso já tem acontecido por intermédio de Institutos e ONGs, inscritos na sociedade como valor eufórico frente ao caráter disfórico que se atribui ao Estado.

O CENPEC, O GIP e o Instituto Paulo Montenegro ${ }^{4}$ apresentaram um Relatório de "Mapeamento das Organizações da Sociedade Civil na Formação

\footnotetext{
${ }^{4}$ https://www.cenpec.org.br/MapeamentoOSCs/ Acesso em: 24 mai.2017.
} 
EID\&A - Revista Eletrônica de Estudos Integrados em Discurso e Argumentação, Ilhéus, n. 16 esp. "Discurso e argumentação na política latino-americana, set.2018.

Docente da Educação Básica". É um estudo revelador de quão intensamente a sociedade civil, por meio de Associações, Centros, Fundações e Institutos ${ }^{5}$ (ao menos 87 entidades não governamentais estão arroladas), arroga-se oferecer soluções e contribuições para o ensino.

Segundo Foucault (2015), uma das funções da sequestração do tempo é organizar e sujeitar o tempo da existência dos homens a esse sistema temporal do ciclo de produção. Não se trata mais somente de fixar os indivíduos ao local, mas ao tempo de interesse da produção.

A mídia de grande distribuição não fez circular os debates sobre a Reforma. O telejornal da Globo, por exemplo, reproduziu as informações do Governo reafirmando-as.

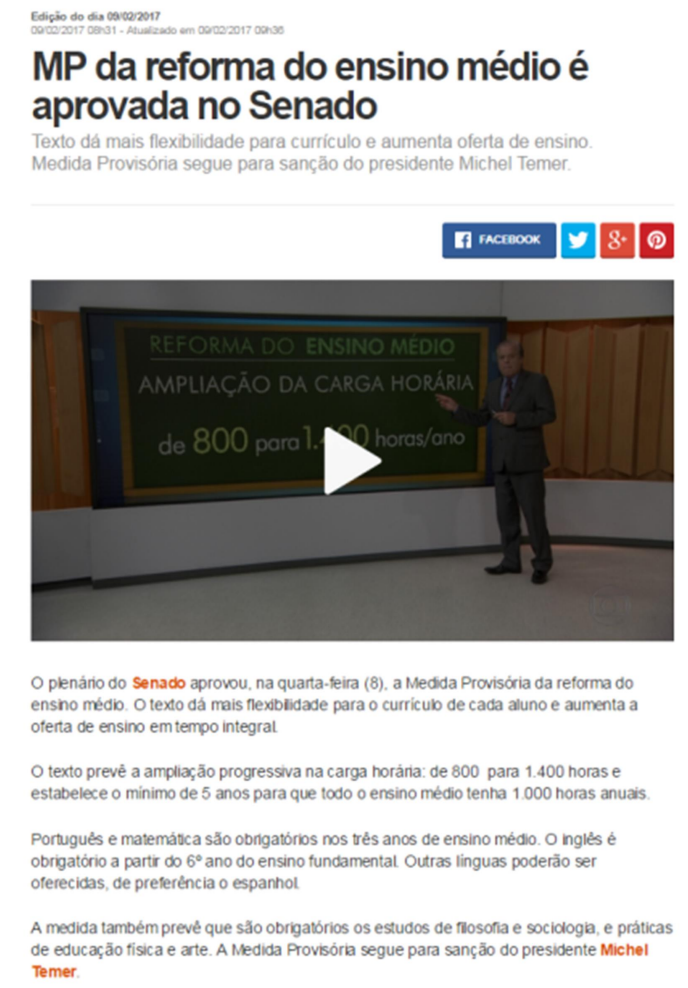

Fonte: http://g1.globo.com/bom-dia-brasil/noticia/2017/02/mp-da-reforma-do-ensinomedio-e-aprovada-no-senado.html

A midiatização deste evento foi feita por meio de campanha governamental que por um processo de deslizamento lexical foi denominada "O Novo Ensino Médio", conforme veremos a seguir.

\footnotetext{
${ }^{5}$ https://www.cenpec.org.br/MapeamentoOSCs/assets/ANEXO_IV.pdf. Acesso em: 24 mai.2017.
} 
EID\&A - Revista Eletrônica de Estudos Integrados em Discurso e Argumentação, Ilhéus, n. 16 esp. "Discurso e argumentação na política latino-americana, set.2018.

\section{Mídia e Política: a campanha publicitária sobre o NOVO Ensino Médio}

Depois de ter sido anunciada, em setembro de 2016, a Medida Provisória que instituiu a Reforma do Ensino Médio foi aprovada pela Câmara no final daquele ano e posteriormente pelo Senado, por 43 votos a 13. A Medida Provisória que institui a reforma do Ensino Médio foi sancionada pelo presidente em 16 de fevereiro de 2017.

Recorreremos ao conceito de vontade de verdade (FOUCAULT, 1971), a respeito do qual se considera que a verdade é da ordem daquilo que um discurso efetivamente diz, exercendo pressão sobre outros discursos, vindo a separar-se deles por um sistema de exclusão. Nessa reflexão foucaultiana, a verdade repousa sobre o verdadeiro e o falso, estando sempre suscetível à desconstrução devido a relações de força.

Objetivando analisar as formas como são produzidas e circulam as diversas notícias sobre a Reforma do Ensino Médio com suas vontades de verdade e como elas servem ao discurso político, analisaremos vídeos publicitários televisivos e vídeos postados em redes sociais em canais de influenciadores digitais.

A campanha do "Novo Ensino Médio" foi composta por várias peças publicitárias para exibição na televisão. A seguir estão expostos os fotogramas de duas peças.
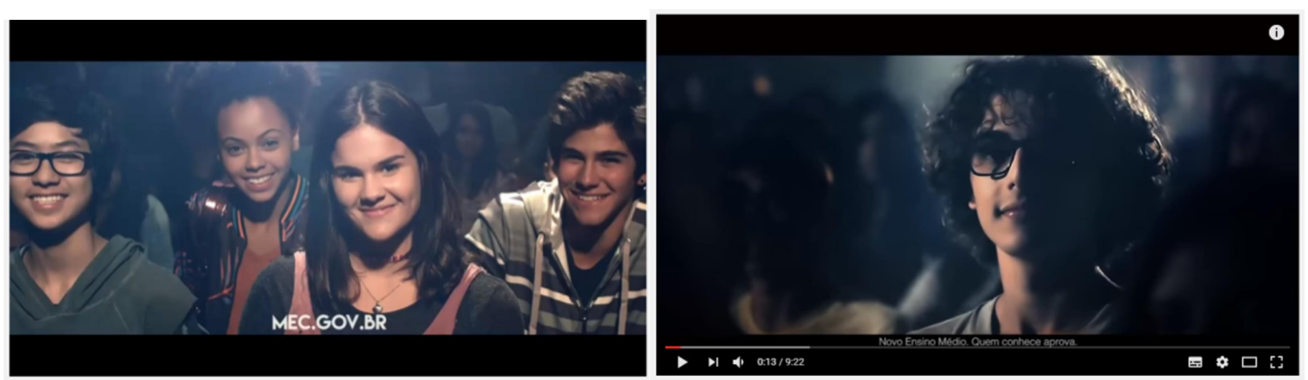

Novo Ensino Médio. Quem conhece, aprova.

-Eu quero fazer jornalismo.

-Eu quero ser professora. É o que eu amo.

-E eu, designer de games.

-Eu quero um curso técnico para já poder trabalhar.

Com o Novo Ensino Médio, você tem mais liberdade para escolher o que estudar, de acordo com a sua vocação. É a liberdade que você queria para decidir o seu futuro.

Quem conhece o Novo Ensino Médio aprova!

Já é assim com 72\% dos brasileiros. (Fonte: Pesquisa IBOPE novembro de 2016)

Fonte: https://www.youtube.com/watch?v=kdERkLO3eTs. Acesso em: 2 ago.2017. 
EID\&A - Revista Eletrônica de Estudos Integrados em Discurso e Argumentação, Ilhéus, n. 16 esp. "Discurso e argumentação na política latino-americana, set.2018.

Além dessas peças, a campanha contou também com vídeos de 60 segundos e peças publicadas em jornais e revistas.
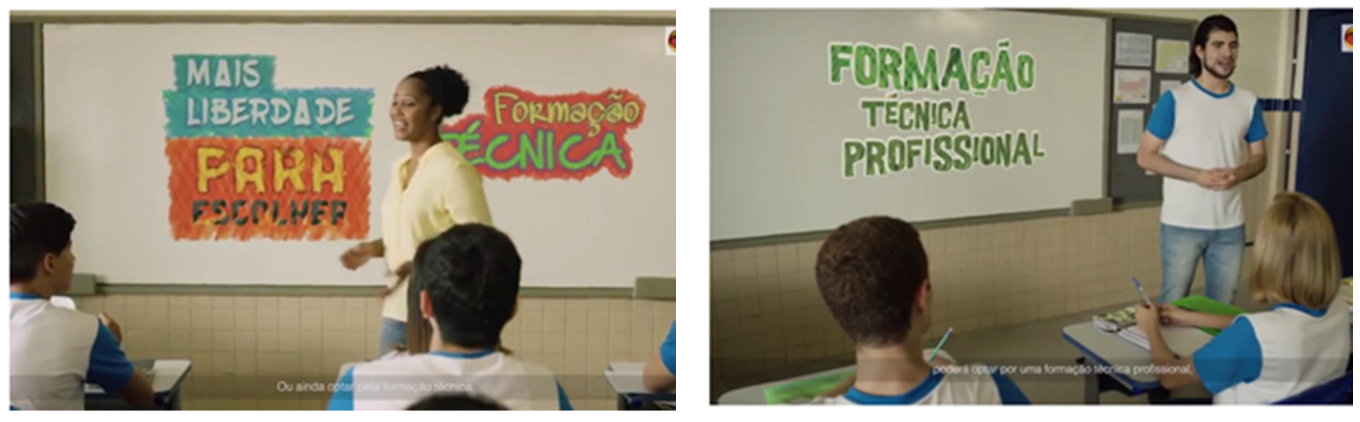

No primeiro vídeo, a professora enfatiza os resultados negativos da Educação brasileira e, portanto, que as mudanças são necessárias - "é prá ontem!". A professora também fala ao aluno do lugar historicamente e supostamente inquestionável da verdade. Com didática e assentimento de seus alunos, explica que eles passarão a ter "liberdade de escolha". No segundo vídeo, um aluno é que se dirige aos colegas de sala de aula para explicar as mudanças do Novo Ensino Médio e a partir de um comparativo genérico de políticas exitosas adotadas em outros países, indica a urgência: “Esse debate já começou”.

Há em várias peças da campanha, composta ainda por outros vídeos, uma recorrência da estrutura composicional e dos argumentos: são sempre atores jovens, que têm suas vozes autorizadas a partir de dados estatísticos; a experiência dos outros países sempre bem sucedidos é que inspiram as mudanças; os alunos estão desestimulados por causa do conteúdo ensinado; o aluno poderá escolher experiências mais atrativas no ensino regular ou sair "Pronto para o trabalho", escolhendo a Formação Técnica. Em todas as peças estão presentes os termos 'liberdade' e 'escolha' e a repetição atua no processo de construção da verdade. As construções frasais logo mostram o contingenciamento da liberdade ou da escolha, mas a recorrência dos termos produz um efeito argumentativo de unidade (ter liberdade) e transparência (ter liberdade é poder escolher), e tornam-se o ponto central do Novo Ensino Médio.

- Eu tenho liberdade [de escolher].

- Eu tenho liberdade de escolher o que estudar de acordo com minha vocação.

- Eu tenho liberdade de escolher entre as quatro áreas ou ensino técnico. 
EID\&A - Revista Eletrônica de Estudos Integrados em Discurso e Argumentação, Ilhéus, n. 16 esp. "Discurso e argumentação na política latino-americana, set.2018.

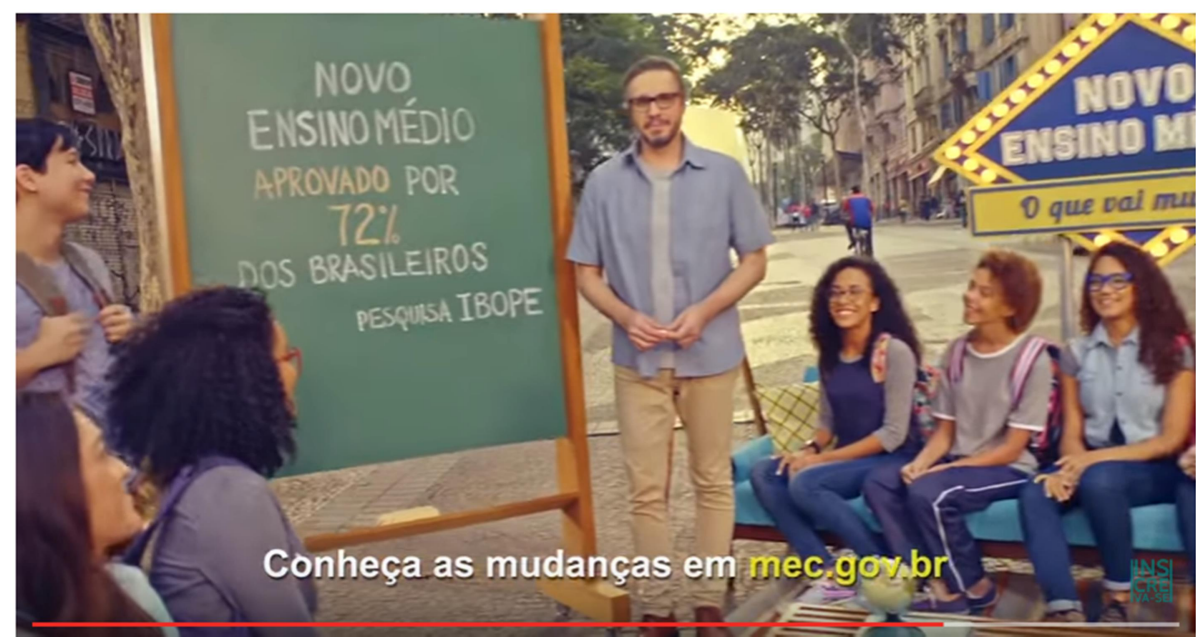

Fonte: Disponível em: https://www.youtube.com/watch?v=4pb1nasqUtQ. Acesso em: 2 ago. 2017

A consultora legislativa na área de Educação na Câmara, Marisa Abreu, na segunda audiência pública informou que o Ensino Médio atende 8,07 milhões de jovens e, considerando os repasses financeiros previstos, o número de alunos a serem atendidos em período integral seria de $257 \mathrm{mil}$ alunos (cerca de 3\% do total, ainda segundo ela das 19.513 escolas de Ensino médio, no máximo 572 viram a serem atendidas). Quanto ao outro ponto de escolha - a flexibilização - a oferta de itinerários formativos também não resiste, porque não há como flexibilizar sem aumentar a desigualdade, nem todos itinerários serão oferecidos em todas as escolas. Nessa checagem, as informações das peças publicitárias tornam-se discutíveis. Elas sustentam-se por uma vontade de verdade (FOUCAULT, 1996) que, na luta de relações de força, angaria adeptos como a própria mídia de massa, que reproduz igualmente na lousa branca (conforme exemplo da notícia dada no telejornal da Globo) o que deve ser tomado como verdade, reafirmando didaticamente (e aí está a lousa desencadeadora desse poder de verdade) que a Reforma do Ensino Médio amplia a carga horária (de todos!). Essa notícia não é falsa, mas continua a reproduzir o que se silencia em todas as campanhas, além do tom e termos eufóricos que acompanham a notícia.

Além da campanha publicitária feita pelo MEC, o Governo Federal contratou influenciadores digitais para produzir vídeos sobre o Novo Ensino Médio: 
EID\&A - Revista Eletrônica de Estudos Integrados em Discurso e Argumentação, Ilhéus, n. 16 esp. "Discurso e argumentação na política latino-americana, set.2018.

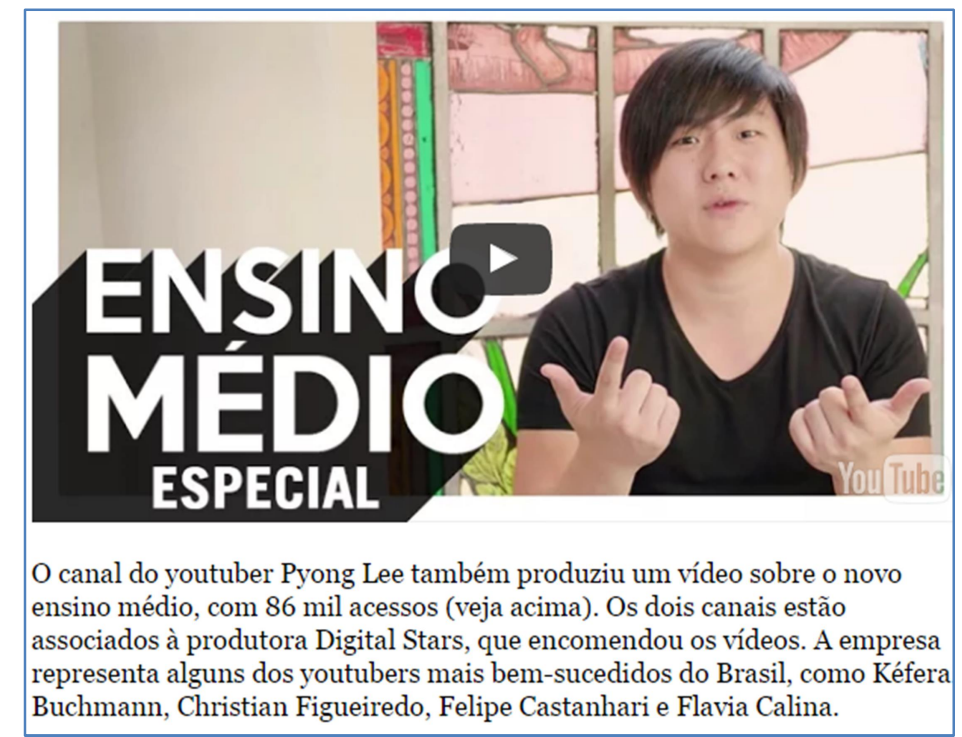

Fonte: http://www1.folha.uol.com.br/educacao/2017/02/1859532-governo-pagayoutubers-para-fazer-elogios-as-mudancas-do-ensino-medio.shtml

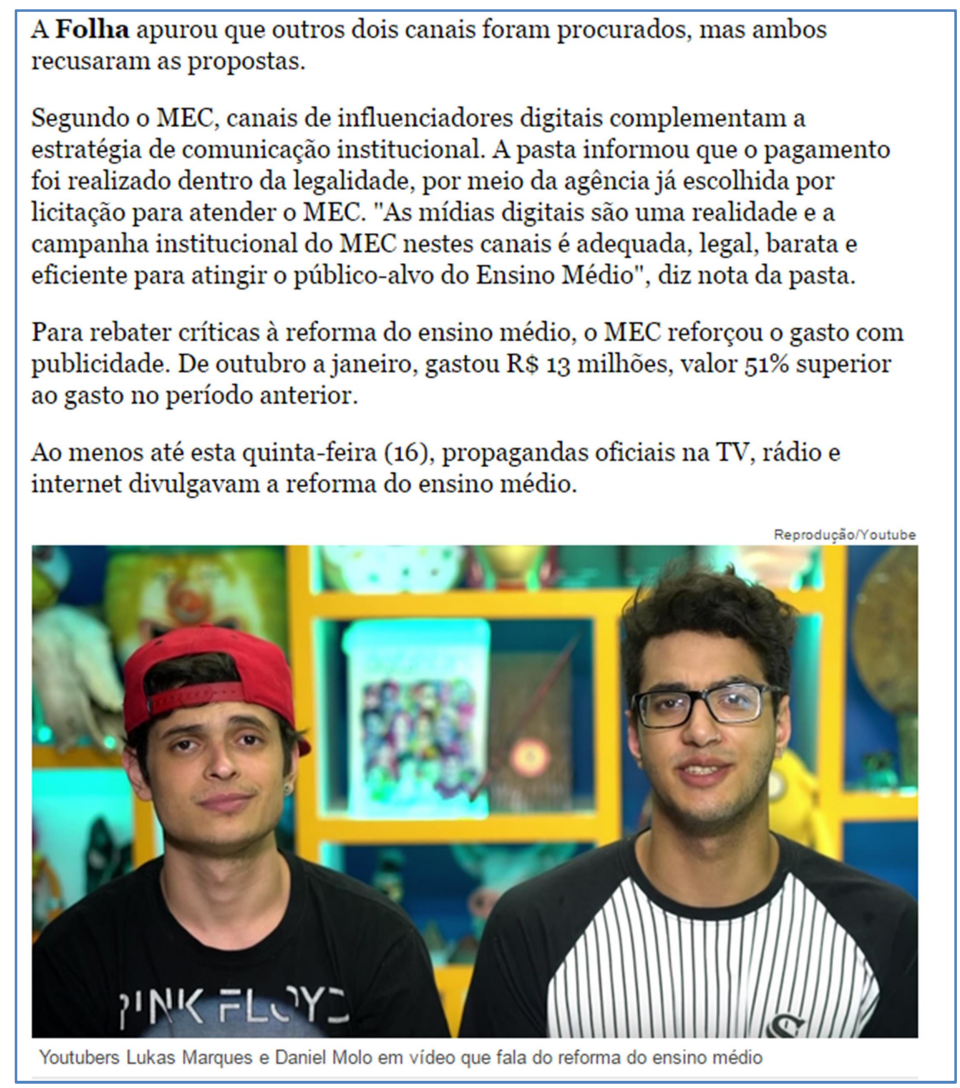

Os influenciadores digitais expressam em seu discurso oethos de um dizer verdadeiro, expondo sobre o assunto supostamente uma opinião pessoal espontânea. Enunciam do lugar do jovem que faz adesão às medidas 
EID\&A - Revista Eletrônica de Estudos Integrados em Discurso e Argumentação, Ilhéus, n. 16 esp. "Discurso e argumentação na política latino-americana, set.2018.

previstas na MP e assim conclamam os seus seguidores a defender a mesma posição. Comparado às peças publicitárias, há neste gênero uma estratégia mais forte de simulação da autenticidade e da credibilidade, uma vez que o sujeito enunciador não é um ator. Na peça publicitária é maior o grau de distanciamento entre o enunciador e enunciatário. Essa distância reduz-se com a estratégia de contratação de 'influenciadores digitais' para atuar na campanha de forma a não explicitar que se trata de uma ação patrocinada. Os seis youtubers contratados expressaram, considerando a proximidade que têm dos seus inúmeros seguidores, as vantagens da Reforma. Trata-se de uma notícia falsa? São diferentes graus de não verdade, uma vez que foram contratados para parecer que dizem a verdade.

\section{Considerações finais}

Os discursos sobre a defesa da Reforma do Ensino Médio reafirmam proposições que estão na base histórica da formação capitalista: fixar os indivíduos ao local, visando ao tempo de interesse da produção; manter o controle da formação e da existência dos sujeitos e conformá-los a um discurso da normatividade que inscreve o indivíduo em toda sua existência em um discurso que não é senão ilusoriamente produzido por ele mesmo, mas por autoridades hierárquicas, por relações de poder presente no próprio sistema de sequestração.

A Reforma do Ensino Médio também está suscetível às formas de poder, que segundo Foucault (2015, p. 205) "não está estritamente localizado nos aparatos estatais, sua ancoragem é bem mais profunda". Em relação à Reforma do Ensino Médio (e também a respeito das outras Reformas em curso neste período) é visível o confronto entre o discurso da igualdade social e o da meritocracia de base neoliberal. O discurso eufórico do aumento de horas no ensino comporta o seu oposto: desigualdade de oferta, que conduz ao rebaixamento da qualidade. E o discurso da autonomia do itinerário formativo pode levar à tutela de interesses do mercado.

Assim, confirmamos nossa suposição de que o discurso que na mídia tradicional ou em campanhas governamentais promove o discurso eufórico de valorização do aumento do tempo na escola dá suporte para sustentar negativamente o discurso dos alunos que resistem, que se rebelam à normatização, reforçando com isso a afirmação pela exclusão que os levam à marginalização. Nessa perspectiva os alunos que ocupam as escolas ou saem 
EID\&A - Revista Eletrônica de Estudos Integrados em Discurso e Argumentação, Ilhéus, n. 16 esp. "Discurso e argumentação na política latino-americana, set.2018.

em manifestos às ruas estariam defendendo a dissipação do tempo por meio da intemperança, imprevidência e desordem (FOUCAULT, 2015), como se não tivessem sapiência e organização e como se ignorassem que nada ocorre fora das relações de poder (FOUCAULT, 1995).

A midiatização da Reforma do Ensino Médio produziu afirmações falsas de liberdade de escolha, silenciou os conflitos e as limitações da nova proposta, sustentou a falsidade dos influenciadores digitais, iludiu com a ideia de que a formação técnica boa é aquela que habilita o aluno a estar "pronto para o trabalho", apoiou-se na grande mídia com telejornais cujos apresentadores reproduzem sem questionar as promessas da MP. A suposta verdade sempre ilustrada na lousa: o poder da escrita no artefato escolar continua a funcionar como fonte de verdade!

\section{Referências}

AB'SABER, T. Dilma Rousseff e o ódio político. São Paulo: Hedra, 2015.

COURTINE, J-J. Metamorfoses do Discurso Político: derivas da fala pública. Org. e trad. Carlos Piovezani e Nilton Milanez. São Carlos: Claraluz, 2006.

FOUCAULT, M. O Sujeito e o Poder. In: RABINOW, Paul; DREYFUS, Hubert. Michel Foucault: uma Trajetória Filosófica - para além do estruturalismo e da hermenêutica. Trad. Vera Porto Carrero. Rio de Janeiro: Forense Universitária, 1995. p. 229-249.

. A ordem do Discurso. Rio de Janeiro: Edições Loyola, 1996 [1971].

. A Vida dos Homens Infames. In: MOTTA, Manoel Barros. Michel Foucault. Estratégia Saber-Poder (Ditos \& Escritos, v. IV). Trad. Vera Lúcia Avellar Ribeiro. Rio de Janeiro: Forense Universitária, 2003. p. 203-222.

. O Nascimento da Biopolítica. São Paulo: Martins Fontes, 2008.

. A sociedade punitiva. Curso do Collège de France. Trad. Ivone C. Benedetti. São Paulo: Editora WMF Martins Fontes, 2015.

PIOVEZANI, C. Verbo, corpo e voz. Dispositivos de fala pública e produção da verdade no discurso político. São Paulo: Unesp, 2009

SARGENTINI, V. (Org.). Mutações do discurso político no Brasil: espetáculo, poder e tecnologias de comunicação. Campinas: Mercado de Letras, 2017.

TODOROV, T. Os inimigos íntimos da democracia. Trad. Joana Angélica D’Avila Melo. São Paulo: Companhia da Letras, 2012. 
EID\&A - Revista Eletrônica de Estudos Integrados em Discurso e Argumentação, Ilhéus, n. 16 esp. "Discurso e argumentação na política latino-americana, set.2018.

Forma de citação sugerida:

SARGENTINI, Vanice. A imposição de reformas e a midiatização: o ensino médio no Brasil entre consensos e resistências. EID\&A - Revista Eletrônica de Estudos Integrados em Discurso e Argumentação, Ilhéus, n. 16 esp. "Discurso e argumentação na política latino-americana”, p. 314-333, set.2018.

Recebido em: 25/07/2018

Aprovado em: 26/08/2018 